\title{
Changing spatial patterns and increasing rurality of HIV prevalence in the Democratic Republic of the Congo between 2007 and 2013
}

Margaret Carrel ${ }^{\mathrm{a}}$, Mark Janko ${ }^{\mathrm{c}, \mathrm{d}}$, Melchior Kashamuka Mwandagalirwa ${ }^{\mathrm{e}}$, Camille Morgan ${ }^{\mathrm{d}}$, Franck Fwamba ${ }^{\dagger}$, Jérémie Muwonga ${ }^{\dagger}$, Antoinette K. Tshefu ${ }^{g}$, Steven Meshnick ${ }^{\mathrm{e}}$, Michael Emch ${ }^{\mathrm{c}, \mathrm{e}}$

a Department of Geographical \& Sustainability Sciences, 303 Jessup Hall, University of lowa, lowa City, IA 52245, USA, T: 319-335-0154, F: , margaret-carrel@uiowa.edu §Corresponding Author

${ }^{\mathrm{b}}$ Department of Epidemiology, University of lowa, lowa City IA, USA

${ }^{\mathrm{C}}$ Department of Geography, CB3220, Carolina Hall, University of North Carolina-Chapel Hill, Chapel Hill, NC, USA

${ }^{\mathrm{d}}$ Department of Biostatistics, CB7420, McGavran-Greenberg Hall, University of North CarolinaChapel Hill, Chapel Hill, NC, USA

${ }^{\text {e}}$ Department of Epidemiology, CB7435, McGavran-Greenberg Hall, University of North Carolina- Chapel Hill, Chapel Hill, NC, USA

${ }^{f}$ National AIDS Control Program (PNLS), Kinshasa, Democratic Republic of the Congo

${ }^{g}$ Ecole de Sante Publique, Faculte de Medecine, University of Kinshasa, Kinshasa, Democratic Republic of the Congo

Support: Research supported by NSF BCS-1339949 (MC, ME, SM) and NIH R01Al107949$01 \mathrm{~A} 1$ (MC, AKT, ME, SM) and NIH R24 HD050924 (MJ). 


\section{Abstract}

The Democratic Republic of the Congo (DRC) has one of the lowest HIV prevalence in subSaharan Africa, estimated at 1.1\% [0.9-1.3] of adults aged 15-49 in 2013 (UNAIDS). Within the 2 million $\mathrm{km}^{2}$ country, however, there exists spatial variation in HIV prevalence, with the highest HIV prevalence observed in the large cities of Kinshasa and Lubumbashi. Globally, HIV is an increasingly rural disease, diffusing outwards from urban centers of high HIV prevalence to places where HIV was previously absent or present at very low levels. Utilizing data collected during Demographic and Health Surveillance (DHS) in 2007 and 2013 in the DRC, we sought to update the map of HIV prevalence in the DRC as well as to explore whether HIV in the DRC is an increasingly rural disease or remains confined to urban areas. Bayesian kriging and regression indicate that HIV prevalence in rural areas of the DRC is higher in 2013 than in 2007 and that increased distance to an urban area is no longer protective against HIV as it was in 2007. These findings suggest that HIV education, testing and prevention efforts need to diffuse from urban to rural areas just as HIV is doing.

Keywords: HIV, Democratic Republic of the Congo, rural, urban, protective, Bayesian kriging 


\section{Introduction}

Despite continuous viral circulation in the country since at least the 1950s, and evidence of Kinshasa as the epicenter of the epidemic as early as the 1920s, the DRC has one of the lowest HIV prevalences in sub-Saharan Africa, estimated at 1.0\% [0.9-1.2] of adults aged 15-49 in 2013 (Faria et al., 2014; UNAIDS, 2014; Vidal et al., 2000; Worobey et al., 2008). While the overall prevalence of HIV in the DRC is low, this national statistic can mask important geographic variation, particularly in a country that stretches over 2 million $\mathrm{km}^{2}$ and is bordered by nine other countries whose HIV prevalence rates in 2013 ranged from 1.0\% [.9-1.1] (Burundi) to 12.5\% [11.9-13.3] (Zambia).

Continual transmission of HIV is of concern in the DRC because of high poverty levels and civil and political unrest which have undermined the public health infrastructure. Data from the 2007 and 2013 Demographic and Health Surveys (DHS) indicate that while HIV testing levels have increased since 2007 they still remain low, with $78 \%$ of women and $84 \%$ of men having never been tested (Ministère du Plan et Suivi de la Mise en oeuvre de la Révolution de la Modernité (MPSMRM) and International, 2014). DHS data also indicate that HIV is more prevalent in urban areas of the DRC than rural areas.

It is widely recognized that early in an epidemic HIV prevalence increases most rapidly in urban areas before diffusing outwards to rural areas (Barongo et al., 1992; Carael, 1997; Dyson, 2003; Solomon et al., 1998). The phenomena was observed in the United States during the 1980s and 1990s: that proximity to a large urban area was a proxy for 
how quickly HIV would diffuse into an area (Golub et al., 1993). The same is true in other places with "mature" HIV epidemics. In 1995, Shabbir and Larson discuss the transition of HIV prevalence from urban to rural areas in Ethiopia, referencing proximity to urban areas and high risk practices among farmers as key driving factors in this transition (Shabbir and Larson, 1995). Buve et al (2002) elaborate on social, behavioral, epidemiological and economic aspects of urbanization that cause this transition. The movement of young people from rural areas to urban areas leads to higher risk sexual behaviors in the absence of stricter family structures and conservative marriage traditions in rural areas (Buvé et al., 2002). Brockerhoff and Biddlecom, for example, found that individuals migrating from urban to rural areas were more likely to engage in high risk sexual behavior than non-migrants (Brockerhoff and Biddlecom, 1999). Urban individuals are more likely to have earlier sexual debut and a higher number of sex partners, increasing their risk of HIV acquisition and transmission (Dodoo et al., 2007).

Pathways for HIV transmission between rural and urban areas are created when young people return to rural areas or when traders or other individuals extend sex networks between rural and urban places (Buvé et al., 2002; Pickering et al., 1996; Pickering et al., 1997). HIV diffuses outwards from cities to rural areas along road and other transit networks, with HIV prevalence decreasing as rurality increases (Coffee et al., 2005; Mnyika et al., 1994; Söderberg et al., 1994; Tanser et al., 2000; Wawer et al., 1991). Rural places then become sites of HIV transmission, often without the treatment or prevention resources that exist in urban areas. While HIV has circulated in the DRC for 
decades, the epidemic there is still relatively youthful, and little research has examined HIV prevalence outside of urban areas (Mulanga-Kabeya et al., 1998). However, in 2007 increased distance from a city was shown to be protective against HIV, following the typical spatial patterns of HIV in a low prevalence context (Messina et al., 2010).

The President's Emergency Plan for AIDS Relief (PEPFAR) is spending $\sim \$ 50$ million over five years in the DRC to combat HIV/AIDS, focusing on issues such as prevention of mother to child transmission (PMTCT), gender based violence and orphans and vulnerable children (OVC) ((ProVIC), 2012). These and other programs tend to focus their work in urban areas of countries for several reasons, including higher HIV prevalence and transmission rates and relative ease of access compared to rural areas. Given the patterns of urban-to-rural HIV diffusion observed in other countries further into their HIV epidemics, however, it is important to understand whether or not this same phenomenon is occurring in DRC, such that programmatic efforts can adapt to the changing nature of the epidemic.

Utilizing data collected during Demographic \& Health Surveys (DHS) in the DRC, we explore how the spatial patterns of HIV have changed between 2007 and 2013. DHS are nationally representative household surveys, meaning they are designed to capture the range of variation in measured outcomes, spanning the rural-urban divide and surveying individuals regardless of risk profile. We investigate whether the relationship between HIV and "rurality" has remained the same between the 2007 and 2013 
surveys, whether it remains confined primarily to populations in and around cities or has become increasingly observed in rural areas of the country.

\section{Data \& Methods}

Household DHS were conducted in the DRC in 2007 and 2013. Groups of households, known as clusters, are selected for survey participation, and latitude/longitude coordinates of the clusters are recorded. Cluster locations are carefully selected to maximize the representativeness of the surveyed population to the population as a whole. Questionnaires are used to generate self-reported data on households and individuals across a range of domain areas, including HIV/AIDS awareness and reproductive health, while biomarker collection is used to provide evidence of disease burden within the population. In the DRC, dried blood spots from finger or heel pricks were used to test the HIV status of surveyed individuals. Due to the personal nature of the data being collected, spatial locations of the DHS clusters are offset randomly. The degree of offset varies between rural and urban clusters, with rural clusters offset by 0 to $5 \mathrm{~km}$ (with $1 \%$ offset by up to $10 \mathrm{~km}$ ) and urban clusters offset by 0 to $2 \mathrm{~km}$. The designation of a cluster as either rural or urban is determined by the country in which the survey is conducted.

The 2007 DRC DHS tested 9275 individuals within 300 clusters for HIV. The 2013 DHS approximately doubled the data collection of 2007 , testing 18,257 individuals within 536 
clusters. For both surveys the split between female and male HIV testing is roughly even. Latitude/longitude coordinates are missing for seven clusters in the 2007 data and 44 clusters in the 2013 data; HIV testing data from those clusters were not considered for further analysis.

Our analysis proceeded in two stages. First, we set out to update the HIV map in DRC from 2007, and develop a descriptive sense of how the underlying spatial distribution may have changed from 2007 to 2013. For each cluster in each survey, we estimated the proportion of individuals testing positive for HIV, and then fit Bayesian generalized linear models with spatial random effects and an intercept as the only covariate. We then used the parameter estimates from these models to predict HIV prevalence across the DRC for 2007 and 2013, a technique known as Bayesian kriging. We adopt a Bayesian approach because it does not require that the underlying random field be Gaussian (which our data are not), nor does it require the covariance function be exactly known, as required by traditional kriging approaches(Pilz and Spöck, 2008). Bayesian methods for kriging have become the gold standard for spatial interpolation since their introduction by Handcock and Stein, and have been widely used for spatial interpolation of infectious disease, including HIV (Coburn and Blower, 2013; Handcock and Stein, 1993; Kleinschmidt et al., 2007).

To develop a sense of how the distribution may have changed from 2007 and 2013, we simply subtract the 2007 map from the 2013 map, making note that doing so only provides a visualization of change across space and time, and no formal way to assess 
change over space and time. We use this descriptive approach, as opposed to formally modeling a spatio-temporal process, because the surveys were largely conducted in different locations in 2007 and 2013, although some of the sampling locations were likely the same as in 2007. As a result, it was not clear how to fit a model to the data that appropriately captured the spatial and temporal correlation structure in the data.

Since the first stage of the analysis can only be used as a visualization, the second stage of analysis was designed to test our hypothesis that HIV is becoming more rural in the DRC. Our exposure of interest was a DHS cluster's distance to the nearest city, which was measured as the Euclidean distance (in kilometers) between each DHS cluster and the nearest major urban area, as defined using the World Cities base layer provided by the Environmental Systems Research Institute (ESRI). These urban areas include national and provincial capitals, major cities and landmark cities ranging in size from under 50,000 to over 1 million people. The exposure measure included cities in countries surrounding the DRC. This was done to account for cross-border movement of people. Given limited mobility in much of the DRC, we assume that many individuals cross international borders into cities in Burundi, Uganda, Zambia, etc. rather than traveling thousands of kilometers to Congolese cities such as Kinshasa and Kisangani. Additionally, we modify the exposure measure by setting the distances between DRCdefined urban areas whose distance to a World City was less than 30 kilometers to zero. This was done to ensure that DHS-defined urban clusters that fell within the city limits of the World Cities layer did not contribute artificial distance measures. Finally, it is important to note that there is a random offset of clusters for participant confidentiality 
purposes. For large distance measures, this offset will not likely change our estimated effect of the exposure in a meaningful way. For small distances, however, effect of the displacement is likely meaningful, although we note that a large number of urban clusters are assigned to have distances of zero, and so the effects of the offset should only be present for rural clusters that are close to major cities. Further, recent work has indicated that the offset does not induce bias in the distance-based measures we conducted (Berggren et al.). Important to note, however, is that because DHS sampled at different locations, the distance measures are not equal across surveys. In 2007, the mean distance to a city was 117 kilometers, while in 2013 it was 142 kilometers, a difference of 25 kilometers ( $p=0.001,95 \% \mathrm{Cl}:-39.8,-9.8)$. While this distance is significant, it is not necessarily meaningful, as movement of individuals to and from major urban centers takes place over larger scales (i.e. in excess of 100 kilometers). However, this difference does interfere with our ability to identify whether or not any change in HIV rurality is due to the diffusion process, or merely an artifact of the data we have at hand.

To test our hypothesis, we pooled the 2007 and 2013 data, and fit a Poisson mixed effects regression model to test the effect of distance to city on prevalence of HIV, and how that effect is changing over time. We adopt a Poisson model because it allows us to directly model the prevalence ratio (also referred to as the relative risk) as a function of the covariates. Briefly, the model has the following form:

$$
\log \left(\operatorname{Pr}\left(Y_{i j}=1 \mid X_{i j}\right)\right)=x_{i j}^{T} \beta+\Lambda_{\mathrm{j}}+\epsilon_{\mathrm{ij}}
$$


Where $\operatorname{Pr}\left(Y_{i j}=1 \mid X_{i j}\right)$ is the probability of HIV infection for respondent $i$ in cluster $j$ given covariates. $x_{i j}^{T}$ is a $1 \times 4$ vector of covariates for each individual. It includes an intercept, a binary indicator for the sex of the survey respondent (with male sex as the reference group), a binary indicator for the year of the survey (2007 or 2013, with 2007 as the reference group), the distance of the survey cluster to the nearest city (in $\mathrm{km}$ ), and an interaction between year and distance to city, which captures the magnitude and direction of the change in effect of our exposure on HIV prevalence. $\beta$ is a $4 \times 1$ vector of regression coefficients linking the covariates to the response via a log link. $\Lambda_{j}$ represents a random intercept at the cluster level that partitions the aggregate error term so as to properly account for the correlation induced by the stratified sampling used by DHS, while $\epsilon_{i j}$ is a pure noise term. Descriptive statistics and model fitting were done in R 3.0.2 (CRAN). Sample weights were used in the calculation of summary HIV prevalence measures but not for mapping or statistical analysis purposes, as recommended by the DHS (Rutstein and Rojas, 2006).

\section{Results}

While the overall prevalence of HIV has fallen slightly (and insignificantly) in the DRC between the 2007 and 2013 DHS, there are distinct differences in how HIV has changed when clusters and individuals are stratified by rural/urban location and sex. HIV in urban clusters dropped between the two DHSs, while rural HIV increased (Figure 2A). The increase in rural HIV is driven by higher prevalence in rural women, HIV prevalence in rural men decreased between the surveys (Figure 2B). 
Interpolation of cluster-level HIV across the DRC (Figure 3A \& 3B) suggests that HIV prevalence increases in the northeast and parts of the southeast, but overall remains low across much of the country. Parameter estimates from the Bayesian kriging are seen in Table 1. Calculating the crude difference in interpolated maps indicates areas that are estimated to have increased or decreased HIV prevalence between 2007 and 2013 (Figure 3C), although these changes are isolated to relatively small pockets of the country. One area of central DRC is, based upon the interpolations, an area of increased HIV prevalence, as is one area in the southeast and small parts of the northeast. Some areas in close proximity to cities appear to have decreased HIV prevalence between the 2007 and 2013 surveys, while other areas, particularly along the border, appear to have increased. Rural clusters in the northeastern province of Orientale and the southeastern province of Katanga, which are hundreds of kilometers from the closest urban area, had particularly high prevalence of HIV (Figure 4). Though the reasons for this are not tested in this paper, these regions of the DRC are in close proximity to Uganda and Sudan and are places with high numbers of both refugees and soldiers (such as in the Lord's Resistance Army), which could be driving the increase in HIV.

Results from the second stage of our analysis suggest that, while distance to a major city was protective in 2007, this protection is disappearing (Table 2). In 2007, for example, increasing distance was associated with a prevalence ratio of 0.996 , whereas in 2013, the effect of distance on prevalence of HIV is 0.999 (which is given by 
exponentiating the sum of the parameter estimates for year and year-by-distance). This decrease in protection is captured by the interaction term between year of survey and distance to city, and indicates that the prevalence ratio from 2007 to 2013 has changed by a factor of $1.004(95 \% \mathrm{Cl}: 1.001,1.006)$. In other words, while a 100-km increase in distance from a city was associated with a $33 \%$ reduction in prevalence in 2007 , that reduction essentially vanishes in 2013 , suggesting that HIV may be slowly diffusing into rural areas. Female sex in both survey years was a risk factor of HIV.

\section{Discussion}

While the DRC remains a low HIV prevalence country, particularly compared to bordering countries such as Zambia, the spatial patterns of infection have shifted in the country since 2007. In particular, it appears that some rural areas of the interior have higher HIV in 2013 than in 2007, though this observation is likely due at least in part to the larger sample size of the 2013 survey which has more data from rural areas. While HIV has decreased in urban populations and in rural men it has increased in rural women, though not significantly so at the national scale. Statistically, it appears that the protective effect of living far from cities that was observed in the 2007 DHS has disappeared in the intervening seven years, consistent with worldwide trends. Potentially this means that rural women who live further from cities now have greater HIV prevalence and/or risk of contracting the virus. 
Previous research into spatial patterns of HIV in sub-Saharan Africa has suggested that a diffusion from high HIV urban areas to relatively lower HIV rural areas takes place.

Data from the early days of the HIV/AIDS epidemic suggested that within the DRC (then Zaire) HIV prevalence depended on circumcision practices, which varied spatially, as well as with proximity to other countries, so that while overall HIV rates were generally low in rural areas they were higher in places that did not practice circumcision or that bordered high HIV countries (MOSES et al., 1990). Other research suggests that HIV prevalence can mask rural/urban differences, and that when incidence is considered rather than prevalence rural areas actually exhibit higher HIV rates (Karim et al., 2011). In Malawi, increased rural prevalence was observed, and distance to major cities was not significantly associated with HIV prevalence, although increased distance to a road or clinic appeared to provide protection against HIV (Bello et al., 2006; Feldacker et al., 2010; Feldacker et al., 2011). In Tanzania, increased HIV prevalence is observed in rural populations, although HIV is higher in small trading centers of rural areas rather than those places that are truly remote (Boerma et al., 1999; Mmbaga et al., 2007; Yahya-Malima et al., 2007). Taken together, these suggest that national estimates of increasing or decreasing HIV prevalence mask important local differences in HIV (Cuadros and Abu-Raddad, 2014).

There are several reasons why the shift in the rural/urban nature of HIV in the DRC may have taken place. The focus of many HIV prevention and treatment programs is in urban areas, given their historically higher HIV prevalence. PEPFAR, for instance, concentrates its efforts in Kinshasa, Lubumbashi and Kisangani, cities of over 1 million 
people. Indeed, the 2013 prevalence of HIV in urban women in the DRC was nearly double that of rural women, though it had decreased since 2007 while rural women's HIV had increased. Changes in the economy and connectivity of the DRC between 2007 and 2013 may also play a role: the road network of the DRC has increased dramatically to facilitate logging and other natural resource extraction. A decline in civil war and violence in the eastern portion of the country may also lead individuals to have higher mobility than they otherwise would, exposing them to greater HIV risk.

Whatever the driving force, it seems that the DRC may now be experiencing the diffusion of HIV outwards from cities into rural areas that has previously been observed in other sub-Saharan countries and globally. Women in the DRC have higher HIV rates than men regardless of rural/urban residence, wealth, education and age. Our findings suggest that HIV prevention programs need to expand their reach into rural areas of the DRC in order to maintain the low levels of HIV prevalence that currently occur there. The large size of the country and the relative inaccessibility of many rural regions makes this difficult, but the expanding nature of economically important transportation networks into previously isolated areas means that patterns of HIV will change as well.

Our analysis considered urban proximity as a trans-national phenomenon, calculating distance to the closest city regardless of country, and assumed that respondents move to and from that nearest city. We assume that individuals move across borders, taking HIV with them, or that economic interactions between rural individuals and urban areas take place with relative ease across borders. This assumption may be stronger in some 
areas of the DRC than others, given vast differences in transportation networks that are artefacts of colonial histories. The use of Euclidean distance to measure proximity to a city is also a limitation in the sense that no person travels in a straight line between their home and a city, and as a result our exposure measure is imperfect. While the transportation network in the DRC has increased dramatically since 2007 , it is still extremely limited by modern standards, many roads are usable only in the dry season and even then are unpaved and heavily rutted. The rail network is virtually nonexistent, though many people make use of the river networks to move around the country. Perhaps calculating a transportation network (either road or river) distance would give different results, although much of the population is not connected to a network at all, making it difficult to make any such measure meaningful. In addition to refining our definitions of distance to city, the definition of rural in our study could be improved with greater information about what constitutes rural in the DRC. As has been shown elsewhere, truly remote and virtually inaccessible villages may have different levels of HIV than do villages that are rural and far from a city but still host markets or bars or clinics (Boerma et al., 1999; Yahya-Malima et al., 2007). The DHS depends on individual countries to classify clusters as rural or urban, so refining this definition would take local ground-truthing or some other methodology.

The observed protective effect of urban proximity on HIV prevalence, with remote populations having less prevalence, in 2007 was no longer present in the 2013 DRC DHS. Interpolated maps of HIV in 2007 and 2013 suggest slowly shifting patterns of HIV, with increased HIV prevalence predicted in some rural areas, and decreasing 
prevalence in and around some major cities within DRC. While urban HIV prevalence is still much higher than rural HIV in the DRC, these findings indicate that prevention and treatment programs will have to address rural residents as well as those who live in the largest cities of the DRC.

\section{Acknowledgements}

Authors were supported by NIH R01Al107949-01A1 and R24 HD050924 and NSF BCS-1339949. . 


\section{References}

(ProVIC), I.H.A.P.i.t.D.R.o.C., 2012. Combating HIV/AIDS in the Democratic Republic of Congo.

Barongo, L.R., Borgdorff, M.W., Mosha, F.F., Nicoll, A., Grosskurth, H., Senkoro, K.P., Newell, J.N., Changalucha, J., Klokke, A.H., Killewo, J.Z., 1992. The epidemiology of HIV-1 infection in urban areas, roadside settlements and rural villages in Mwanza Region, Tanzania. AIDS 6, 1521-1528.

Bello, G.A., Chipeta, J., Aberle-Grasse, J., 2006. Assessment of trends in biological and behavioural surveillance data: is there any evidence of declining HIV prevalence or incidence in Malawi? Sexually transmitted infections 82, i9-i13.

Berggren, G.G., Berggren, W.L., Menager, H., Genece, E., 1997. Longitudinal community health research for equity and accountability in primary health care in Haiti. Boerma, J., Urassa, M., Senkoro, K., Klokke, A., Ngweshemi, J., 1999. Spread of HIV infection in a rural area of Tanzania. AIDS 13, 1233-1240.

Brockerhoff, M., Biddlecom, A.E., 1999. Migration, sexual behavior and the risk of HIV in Kenya. International Migration Review, 833-856.

Buvé, A., Bishikwabo-Nsarhaza, K., Mutangadura, G., 2002. The spread and effect of HIV-1 infection in sub-Saharan Africa. The Lancet 359, 2011-2017.

Carael, M., 1997. Urban-rural differentials in HIV/STDs and sexual behaviour. Sexual cultures and migration in the era of AIDS: Anthropological and demographic perspectives, 107-126.

Coburn, B.J., Blower, S., 2013. Mapping HIV epidemics in sub-Saharan Africa with use of GPS data. The lancet global health 1, e251-e253.

Coffee, M., Lurie, M.N., Garnett, G.P., 2007. Modelling the impact of migration on the HIV epidemic in South Africa. AIDS (London, England) 21, 343-350.

Coffee, M.P., Garnett, G.P., Mlilo, M., Voeten, H.A., Chandiwana, S., Gregson, S., 2005. Patterns of movement and risk of HIV infection in rural Zimbabwe. Journal of Infectious Diseases 191, S159-S167.

Crosby, R.A., Yarber, W.L., DiClemente, R.J., Wingood, G.M., Meyerson, B., 2002. HIVassociated histories, perceptions, and practices among low-income African American women: Does rural residence matter? American Journal of Public Health 92, 655-659.

Cuadros, D.F., Abu-Raddad, L.J., 2014. Spatial variability in HIV prevalence declines in several countries in sub-Saharan Africa. Health \& place 28, 45-49. 
Dodoo, F.N.-A., Zulu, E.M., Ezeh, A.C., 2007. Urban-rural differences in the socioeconomic deprivation-sexual behavior link in Kenya. Social science \& medicine 64, 1019-1031.

Dyson, T., 2003. HIV/AIDS and urbanization. Population and development review 29, 427-442.

Emch, M., Ali, M., Acosta, C., Yunus, M., Sack, D.A., Clemens, J.D., 2007. Efficacy calculation in randomized trials: global or local measures? Health \& place 13, 238-248.

Faria, N.R., Rambaut, A., Suchard, M.A., Baele, G., Bedford, T., Ward, M.J., Tatem, A.J., Sousa, J.D., Arinaminpathy, N., Pépin, J., 2014. The early spread and epidemic ignition of HIV-1 in human populations. Science 346, 56-61.

Feldacker, C., Emch, M., Ennett, S., 2010. The who and where of HIV in rural Malawi: Exploring the effects of person and place on individual HIV status. Health \& place 16, 996-1006.

Feldacker, C., Ennett, S.T., Speizer, I., 2011. It's not just who you are but where you live: An exploration of community influences on individual HIV status in rural Malawi. Social science \& medicine $72,717-725$.

Golub, A., Gorr, W.L., Gould, P.R., 1993. Spatial diffusion of the HIV/AIDS epidemic: modeling implications and case study of AIDS incidence in Ohio. Geographical Analysis 25, 85-100.

Handcock, M.S., Stein, M.L., 1993. A Bayesian analysis of kriging. Technometrics 35, 403-410.

Kamali, A., Carpenter, L.M., Whitworth, J.A.G., Pool, R., Ruberantwari, A., Ojwiya, A., 2000. Seven-year trends in HIV-1 infection rates, and changes in sexual behaviour, among adults in rural Uganda. AIDS 14, 427-434.

Karim, Q.A., Kharsany, A.B., Frohlich, J.A., Werner, L., Mashego, M., Mlotshwa, M., Madlala, B.T., Ntombela, F., Abdool Karim, S.S., 2011. Stabilizing HIV prevalence masks high HIV incidence rates amongst rural and urban women in KwaZulu-Natal, South Africa. International journal of epidemiology 40, 922-930.

Kleinschmidt, I., Pettifor, A., Morris, N., MacPhail, C., Rees, H., 2007. Geographic distribution of human immunodeficiency virus in South Africa. The American Journal of Tropical Medicine and Hygiene 77, 1163-1169.

McKinney, M.M., 2002. Variations in rural AIDS epidemiology and service delivery models in the United States. The Journal of Rural Health 18, 455-466. 
Messina, J.P., Emch, M., Muwonga, J., Mwandagalirwa, K., Edidi, S.B., Mama, N., Okenge, A., Meshnick, S.R., 2010. Spatial and socio-behavioral patterns of HIV prevalence in the Democratic Republic of Congo. Social science \& medicine 71, 14281435.

Ministère du Plan et Suivi de la Mise en oeuvre de la Révolution de la Modernité (MPSMRM), M.d.I.S., International, P.M.a.I., 2014. Democratic Republic of Congo Demographic and Health Survey 2013-14: Key Findings, Rockville, Maryland, USA.

Mmbaga, E.J., Hussain, A., Leyna, G.H., Holm-Hansen, C., Mnyika, K.S., Sam, N.E., Klouman, E., Klepp, K.-I., 2007. Trends in HIV-1 prevalence and risk behaviours over 15 years in a rural population in Kilimanjaro region of Tanzania. AIDS Res Ther 4, 23.

Mmbaga, E.J., Leyna, G.H., Hussain, A., Mnyika, K.S., Sam, N.E., Klepp, K.-I., 2008. The role of in-migrants in the increasing rural HIV-1 epidemic: results from a village population survey in the Kilimanjaro region of Tanzania. International Journal of Infectious Diseases 12, 519-525.

Mnyika, K.S., Klepp, K.-I., Kvåle, G., Nilssen, S., Kissila, P.E., Ole-King'ori, N., 1994. Prevalence of HIV-1 infection in urban, semi-urban and rural areas in Arusha region, Tanzania. AIDS 8, 1477-1482.

Morgan, D., Mahe, C., Mayanja, B., Okongo, J.M., Lubega, R., Whitworth, J.A., 2002. HIV-1 infection in rural Africa: is there a difference in median time to AIDS and survival compared with that in industrialized countries? AIDS 16, 597-603.

MOSES, S., BRADLEY, J.E., NAGELKERKE, N.J.D., RONALD, A.R., NDINYAACHOLA, J.O., PLUMMER, F.A., 1990. Geographical Patterns of Male Circumcision Practices in Africa: Association with HIV Seroprevalence. International journal of epidemiology 19, 693-697.

Mulanga-Kabeya, C., Nzilambi, N., Edidi, B., Minlangu, M., Tshimpaka, T., Kambembo, L., Atibu, L., Mama, N., llunga, W., Sema, H., 1998. Evidence of stable HIV seroprevalences in selected populations in the Democratic Republic of the Congo. AIDS 12, 905-910.

Mulder, D.W., Nunn, A., Kamali, A., Nakiyingi, J., Wagner, H., Kengeya-Kayondo, J., 1994. Two-year HIV-1-associated mortality in a Ugandan rural population. The Lancet $343,1021-1023$.

Pickering, H., Okongo, M., Bwanika, K., Nnalusiba, B., Whitworth, J., 1996. Sexual mixing patterns in Uganda: small-time urban/rural traders. AIDS 10, 533-536. Pickering, H., Okongo, M., Ojwiya, A., Yirrell, D., Whitworth, J., 1997. Sexual networks in Uganda: mixing patterns between a trading town, its rural hinterland and a nearby fishing village. International journal of STD \& AIDS 8, 495-500. 
Pilz, J., Spöck, G., 2008. Why do we need and how should we implement Bayesian kriging methods. Stochastic Environmental Research and Risk Assessment 22, 621632.

Rutstein, S.O., Rojas, G., 2006. Guide to DHS statistics. Calverton, Maryland: ORC Macro.

Shabbir, I., Larson, C., 1995. Urban to rural routes of HIV infection spread in Ethiopia. The Journal of tropical medicine and hygiene 98, 338-342.

Sinha, G., Dyalchand, A., Khale, M., Kulkarni, G., Vasudevan, S., Bollinger, R.C., 2008. Low utilization of HIV testing during pregnancy: What are the barriers to HIV testing for women in rural India? JAIDS Journal of Acquired Immune Deficiency Syndromes 47, 248-252.

Söderberg, S., Temihango, W., Kadete, C., Ekstedt, B., Masawe, A., Vahlne, A., Horal, P., 1994. Prevalence of HIV-1 infection in rural, semi-urban and urban villages in southwest Tanzania: estimates from a blood-donor study. AIDS 8, 971-976.

Solomon, S., Kumarasamy, N., Ganesh, A., Amalraj, R.E., 1998. Prevalence and risk factors of HIV-1 and HIV-2 infection in urban and rural areas in Tamil Nadu, India. International journal of STD \& AIDS 9, 98-103.

Stephenson, J., 2000. Rural HIV/aids in the united states. Jama 284, 167-168.

Tanser, F., LeSueur, D., Solarsh, G., Wilkinson, D., 2000. HIV heterogeneity and proximity of homestead to roads in rural South Africa: an exploration using a geographical information system. Tropical Medicine \& International Health 5, 40-46. UNAIDS, 2014. HIV and AIDS Estimates, 2014.

Vidal, N., Peeters, M., Mulanga-Kabeya, C., Nzilambi, N., Robertson, D., llunga, W., Sema, H., Tshimanga, K., Bongo, B., Delaporte, E., 2000. Unprecedented degree of human immunodeficiency virus type 1 (HIV-1) group M genetic diversity in the Democratic Republic of Congo suggests that the HIV-1 pandemic originated in Central Africa. Journal of virology 74, 10498-10507.

Wawer, M.J., Serwadda, D., Musgrave, S.D., Konde-Lule, J.K., Musagara, M., Sewankambo, N.K., 1991. Dynamics of spread of HIV-I infection in a rural district of Uganda. Bmj 303, 1303-1306.

Worobey, M., Gemmel, M., Teuwen, D.E., Haselkorn, T., Kunstman, K., Bunce, M., Muyembe, J.-J., Kabongo, J.-M.M., Kalengayi, R.M., Van Marck, E., 2008. Direct evidence of extensive diversity of HIV-1 in Kinshasa by 1960. Nature 455, 661-664. 
Yahya-Malima, K.I., Matee, M.I., Evjen-Olsen, B., Fylkesnes, K., 2007. High potential of escalating HIV transmission in a low prevalence setting in rural Tanzania. BMC Public Health 7, 1-10. 


\section{Figures}

Figure 1. Location of DHS clusters in 2007 and 2013 (circles) and of cities in the DRC and bordering countries (squares).

Figure 2. HIV prevalence in the 2007 and 2013 DHS, stratified by urban/rural residence (A) and by sex (B).

Figure 3. Interpolated HIV prevalence in 2007 (A) and 2013 (B) surveys. Difference in interpolated HIV prevalence between 2007 and 2013 (C) with location of cities indicated. Areas in green have lower interpolated HIV prevalence in 2013 than in 2007, areas in red have increased HIV.

Figure 4. Measured HIV prevalence in rural clusters in the 2007 and 2013 DHS.

Clusters are scaled according to the level of HIV prevalence. Urban clusters have been omitted from the map. 
Tables

\begin{tabular}{|l|l|l|l|l|l|l|}
\hline & \multicolumn{4}{|l|}{2007} & 2013 & \\
\hline Parameter & Estimate & Lower Crl & Upper Crl & Estimate & Lower Crl & Upper Crl \\
\hline Intercept & -4.69 & -5.02 & -4.41 & -5.323 & -5.68 & -5.00 \\
\hline Sigma.sq & 0.95 & 0.53 & 1.56 & 1.52 & 0.92 & 2.27 \\
\hline phi & 24.68 & 0.93 & 48.65 & 24.39 & 0.53 & 48.67 \\
\hline
\end{tabular}

Table 1. Parameter estimates from Bayesian kriging of HIV prevalence in DHS clusters in 2007 and 2013. 


\begin{tabular}{|l|l|l|l|l|}
\hline & Prevalence Ratio & $\mathrm{p}$-value & Lower Cl & Upper Cl \\
\hline Intercept & 0.007 & $<0.001$ & 0.004 & 0.009 \\
\hline Sex (Female =1, male=0) & 2.180 & $<0.001$ & 1.794 & 2.740 \\
\hline Year & 0.481 & 0.003 & 0.322 & 0.726 \\
\hline Distance to City & 0.996 & 0.002 & 0.993 & 0.998 \\
\hline Year $x$ Distance to City & 1.004 & 0.035 & 1.001 & 1.006 \\
\hline
\end{tabular}

Table 2. Results from Poisson mixed effects model of HIV on distance to city (adjusted for sex and year of survey). 


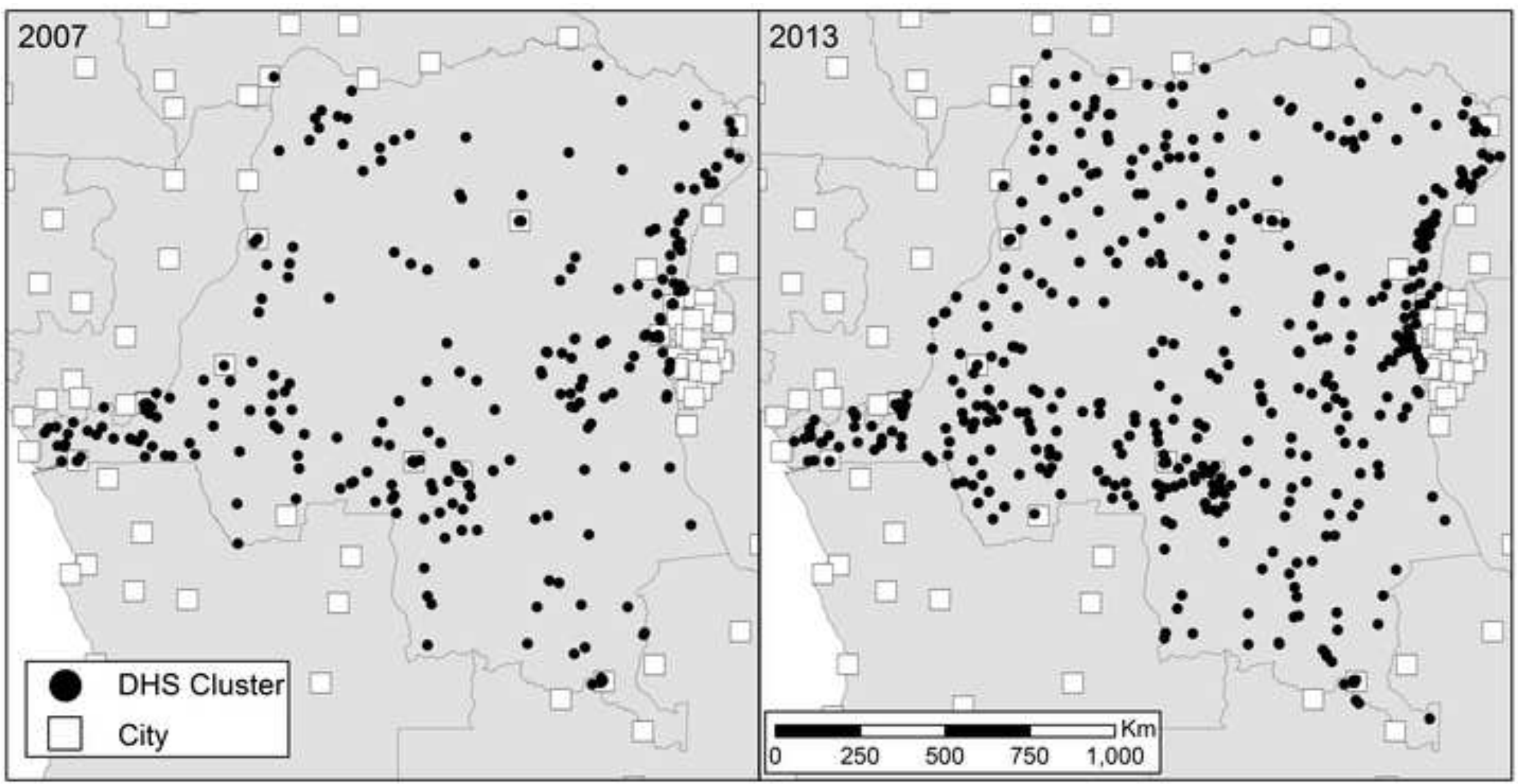


A

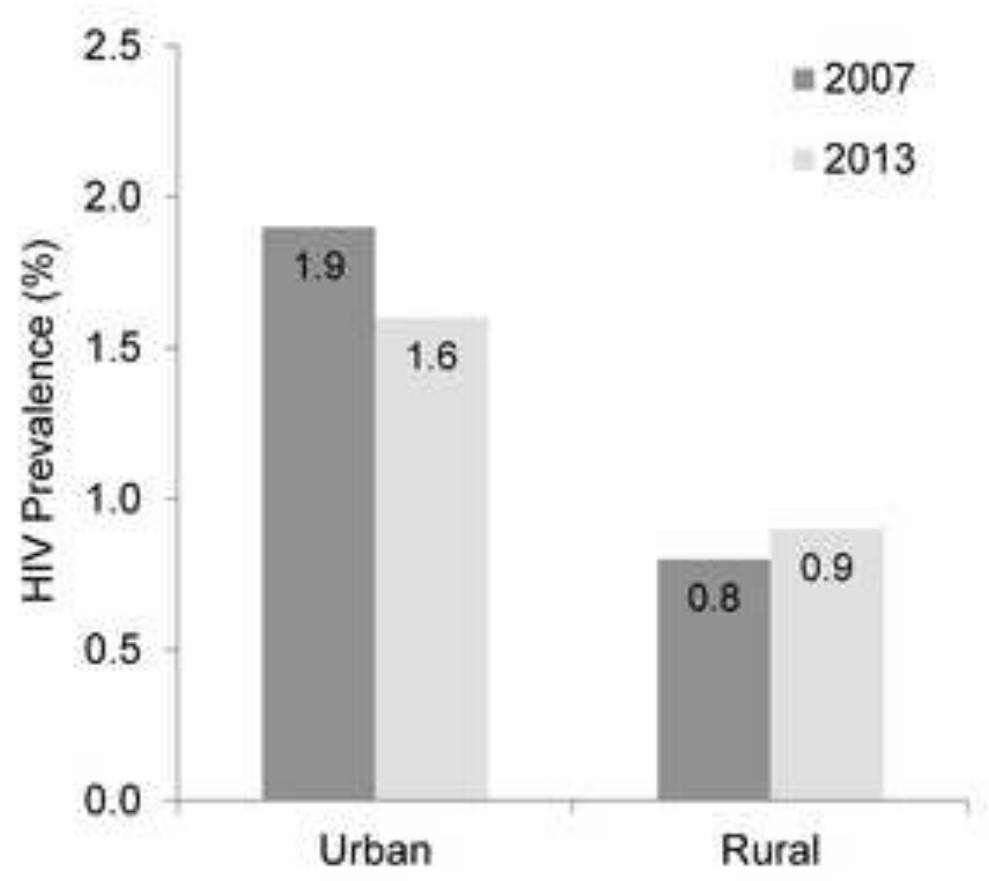

B

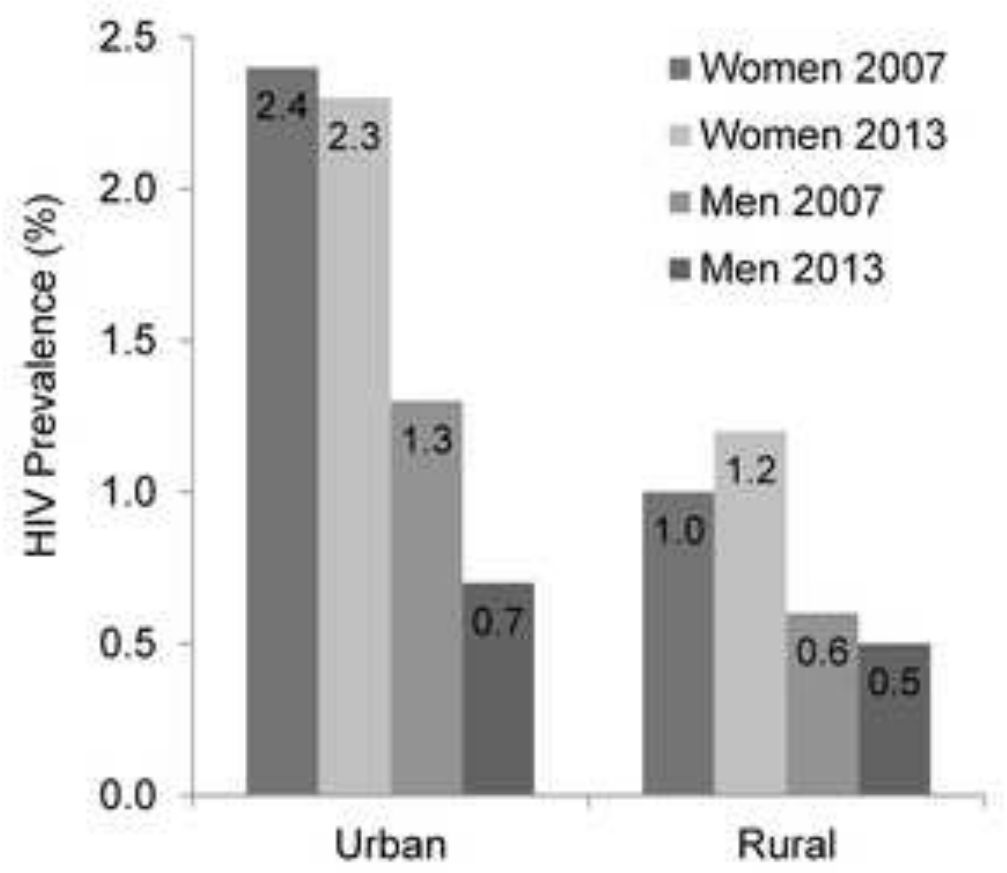




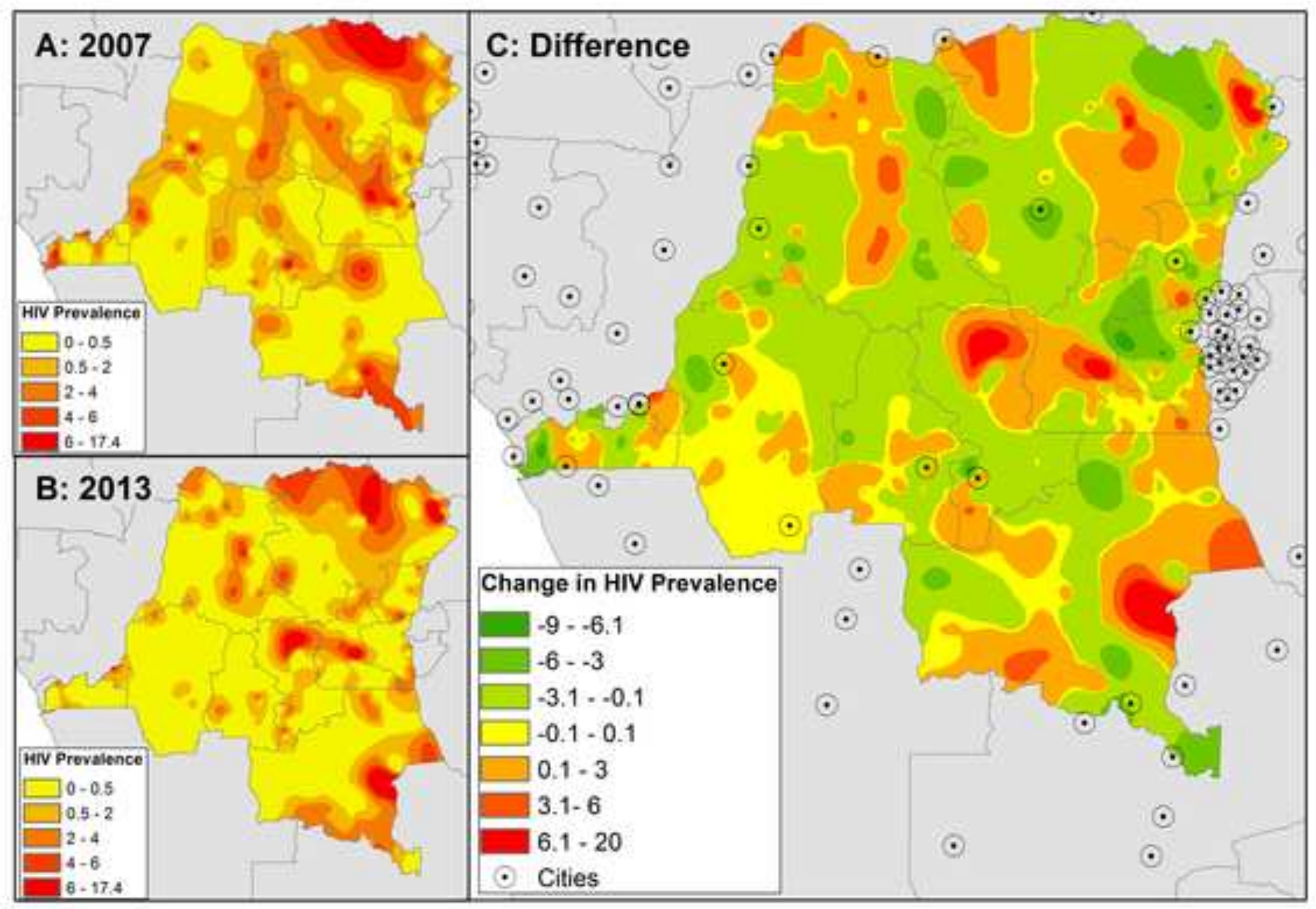




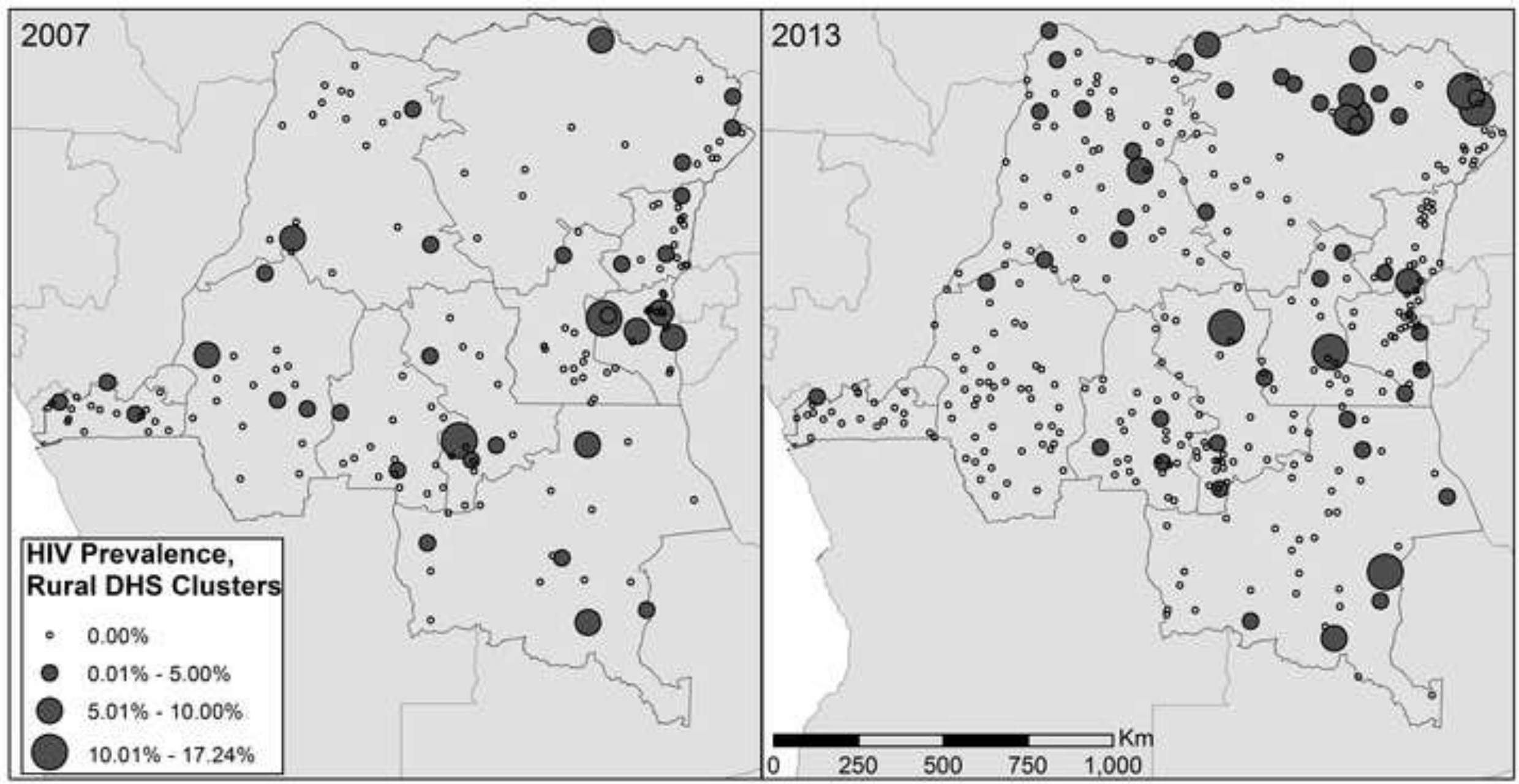

